\title{
Treatment of Human Lens Epithelium with High Levels of Nanoceria Leads to Reactive Oxygen Species Mediated Apoptosis
}

\author{
Belal I. Hanafy ${ }^{1}{ }^{\mathbb{D}}$, Gareth W. V. Cave ${ }^{1}$, Yvonne Barnett ${ }^{1,2}$ and Barbara Pierscionek ${ }^{1,3, *}$ \\ 1 School of Science and Technology, Nottingham Trent University, Clifton Lane, Nottingham NG11 8NS, UK; \\ belal.hanafy2017@my.ntu.ac.uk (B.I.H.); gareth.cave@ntu.ac.uk (G.W.V.C.); \\ Yvonne.barnett@anglia.ac.uk (Y.B.) \\ 2 Faculty of Science and Technology, Anglia Ruskin University, East Road, Cambridgeshire CB1 1PT, UK \\ 3 School of Life Science and Education, Staffordshire University College Road, Stafford ST4 2DE, UK \\ * Correspondence: barbara.pierscionek@staffs.ac.uk; Tel.: +447952248455
}

Received: 20 December 2019; Accepted: 16 January 2020; Published: 21 January 2020

\begin{abstract}
Nanoceria (cerium oxide nanoparticles) have been shown to protect human lens epithelial cells (HLECs) from oxidative stress when used at low concentrations. However, there is a lack of understanding about the mechanism of the cytotoxic and genotoxic effects of nanoceria when used at higher concentrations. Here, we investigated the impact of 24-hour exposure to nanoceria in HLECs. Nanoceria's effects on basal reactive oxygen species (ROS), mitochondrial morphology, membrane potential, ATP, genotoxicity, caspase activation and apoptotic hallmarks were investigated. Scanning electron microscopy-energy dispersive X-ray spectroscopy (SEM-EDX) studies on isolated mitochondria revealed significant uptake and localization of nanoceria in the mitochondria. At high nanoceria concentrations $\left(400 \mu \mathrm{g} \mathrm{mL}^{-1}\right)$, intracellular levels of ROS were increased and the HLECs exhibited classical hallmarks of apoptosis. These findings concur with the cells maintaining normal ATP levels necessary to execute the apoptotic process. These results highlight the need for nanoceria dose-effect studies on a range of cells and tissues to identify therapeutic concentrations in vitro or in vivo.
\end{abstract}

Keywords: apoptosis; genotoxicity; reactive oxygen species; cerium oxide; mitochondria

\section{Introduction}

Nanoparticles offer great potential as medical devices due to their unique physicochemical properties [1-3]. For example, cerium oxide nanoparticles "nanoceria" are extensively researched for biomedical and drug delivery applications because of their unique recyclable antioxidant, neuroprotective, radioprotective and anti-inflammatory properties [4-8]. These properties arise from the ability of cerium ions to co-exist and transition between trivalent and tetravalent oxidation states $\left(\mathrm{Ce}^{3+}, \mathrm{Ce}^{4+}\right)$ at the surface defects present in the $\mathrm{CeO}_{2}$ crystalline structure allowing nanoceria to release or acquire oxygen depending on the ambient environment $[9,10]$. Additionally, nanoceria are increasingly used for industrial applications such as an additive to diesel fuel (commercially available under several trade names such as Envirox $\left.{ }^{\mathrm{TM}}\right)$ to reduce soot emissions and decrease fuel consumption [11,12]. This has led to increased exposure to nanoceria which warrants investigation of their toxicological effects and interactions with various eukaryotic cells. As such, nanoceria was considered a high priority for toxicological evaluation [12,13].

Despite the exponential rise in the use of new nanomaterials, nanotoxicological evaluation is not carried out with a similarly high rate [14]. Hence, assessing and evaluating the biocompatibility of nanomaterials are crucial issues for both the public and the scientific community to enable informed 
decisions to be made regarding their use. Various studies have focused on the toxicity mechanism of different types of nanoparticles, such as $\mathrm{Ag}, \mathrm{Zn}$, and $\mathrm{Si}$, in different cell lines in investigations of oxidative stress as a cause of toxicity [3]. Cerium oxide nanoparticles are unique as they possess inherent antioxidant properties and hence, studying their ability to induce oxidative stress presents a novel and crucial perspective on their potential function and application. The toxicity of nanoceria has been studied in various in vivo and in vitro models and more investigations into the mechanism of their action are needed [13]. Additionally, many of the toxicological studies are performed on nanoceria with unknown or poor colloidal stability, a common problem for nanoceria, which gives rise to conflicting toxicological profiles. Although nanoceria are known for their powerful antioxidant properties, some studies have reported their ability to cause oxidative stress $[13,15,16]$. Ocular exposure is of particular interest due to the ease for sustained environmental exposure. Although nanoceria have shown promise in treating some ocular diseases such as retinal degeneration [17], corneal inflammation [18], glaucoma [19], and cataracts [20], there is a paucity of knowledge about toxicity mechanism of nanoceria in any ocular tissue. The human lens epithelial cell line (HLEC) provides a suitable model for studying toxicity of nanoceria on the eye lens, as these cells are the lenticular stem cells from which the lens fiber cells differentiate. Damage to the lens epithelium disrupts protein expression and could lead to aggregation of proteins that causes light scatter and manifests as cataract [21].

Recently, it has been shown that highly stable and well characterized monodisperse cerium oxide nanoparticles $(4 \mathrm{~nm})$ coated with ethylene glycol and its acetate derivatives, ie ethylene glycol coated nanoparticles (EGCNPs) can protect HLECs from oxidative stress when used in concentrations as low as $50 \mu \mathrm{g} \mathrm{mL}^{-1}$, and the nanoparticles were non-cytotoxic up to $200 \mu \mathrm{g} \mathrm{mL} \mathrm{L}^{-1}$ [20]. When the concentration of nanoceria was increased to $400 \mu \mathrm{g} \mathrm{mL}-1$, a decrease in viability, measured by MTT assay, was observed. However, the cells were still able to proliferate normally for over three days without signs of necrotic damage [20]. This suggest that the nanoparticles at this concentration could interfere with mitochondrial functions and this has warranted further investigation.

In this study, we investigated the mechanism of toxicity caused by short-term exposure to different doses of EGCNPs. Here, we report the effect of different EGCNPs concentrations on various cellular parameters. The results show that although nanoceria have antioxidant properties at low doses $\left(<200 \mu \mathrm{g} \mathrm{mL}^{-1}\right)$ and do not interfere with basal ROS that are needed for normal cell signaling and metabolic functions [22]. At a higher dose $\left(400 \mu \mathrm{g} \mathrm{mL}^{-1}\right)$ they induce reactive oxygen species (ROS) generation that mediates cellular apoptosis. It is clearly demonstrated that cell death is driven by the mitochondrial apoptotic pathway, wherein ROS-mediated mitochondrial membrane depolarization is followed by DNA damage and caspase cascade activation. To date, this is the first report on the mechanism of nanoceria toxicity in lens cells.

\section{Results}

\section{EGCNPs Characterization}

EGCNPs were thoroughly characterized in our previous work using transmission electron microscopy, powder X-ray diffraction, dynamic light scattering, thermogravimetric analysis, gas chromatography-mass spectroscopy, Fourier transform infrared spectroscopy (FTIR), UV-Vis spectroscopy [20]. Briefly, EGCNPs were spherical in shape with a core size (TEM) of $4.0 \pm 0.8 \mathrm{~nm}$ (Figure 1) and crystallite size (XRD, Scherrer formula) of $3.5 \mathrm{~nm}$. EGCNPs were stable in aqueous media for at least seven days with minimum sedimentation. The zeta potential was $+44 \mathrm{mV}$ in water and $-9.7 \mathrm{mV}$ in cell culture media due to protein coronae formation. EGCNPs were monodisperse with unimodal distribution of intensity-weighted mean hydrodynamic diameters as was demonstrated by DLS [20]. 


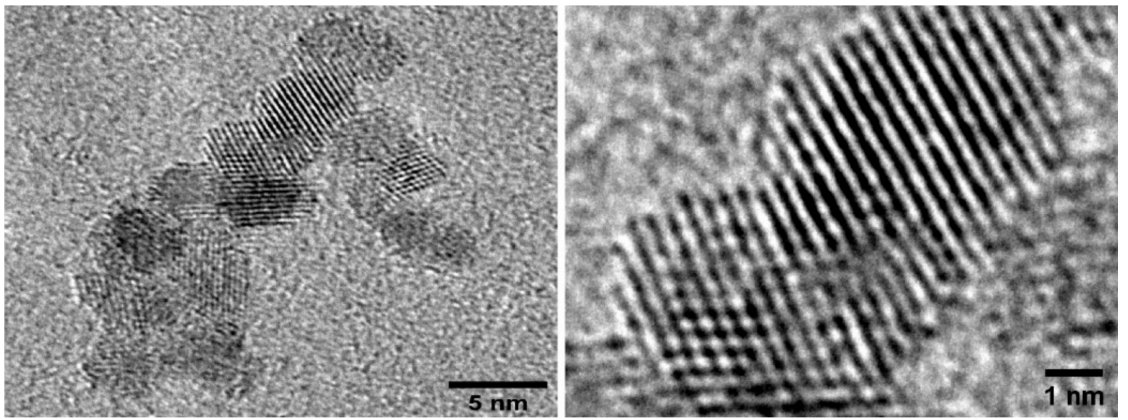

Figure 1. TEM micrographs of ethylene glycol coated nanoparticles EGCNPs showing the spherical, monodisperse and crystalline nature of the nanoparticles.

Acute Exposure to High EGCNPs Concentrations Increases Basal ROS

Overproduction of reactive oxygen species (ROS) is one of the most common pathways involved in nanomaterial toxicity [14]. Therefore, the basal ROS level in HLECs was measured after $24 \mathrm{~h}$ exposure to different EGCNPs concentrations $\left(0,50,100,200\right.$, and $\left.400 \mu \mathrm{g} \mathrm{mL}{ }^{-1}\right)$ using the H2DCFDA probe. H2DCFDA is a non-fluorescent cell-permeable probe which is cellularly retained upon internalization due to deacetylation, and then oxidized by the action of ROS into highly fluorescent DCF enabling the estimation of ROS levels. As shown in Figure 2, EGCNPs concentrations up to $200 \mu \mathrm{g} \mathrm{mL}^{-1}$ did not lead to any significant alteration to the basal ROS level when compared to control cells $(p>0.05)$. Conversely, when the concentration was increased to $400 \mu \mathrm{g} \mathrm{mL}{ }^{-1}$, a significant elevation in ROS level was observed.

(A)

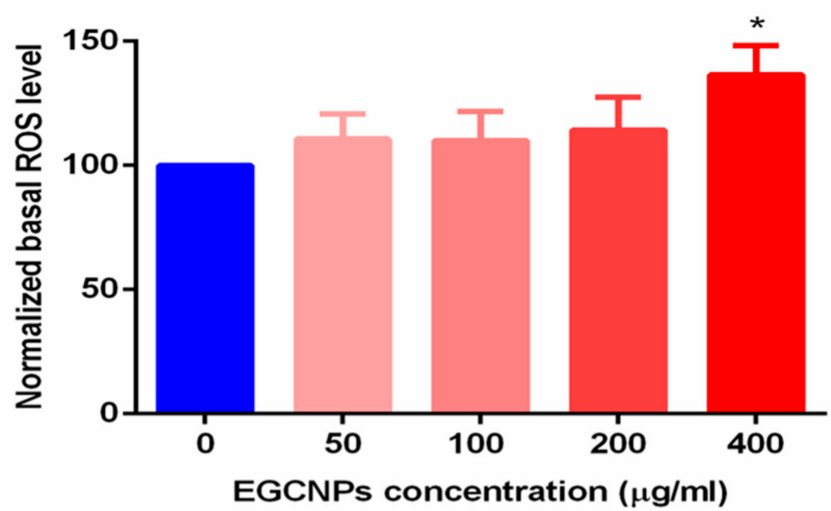

(B)
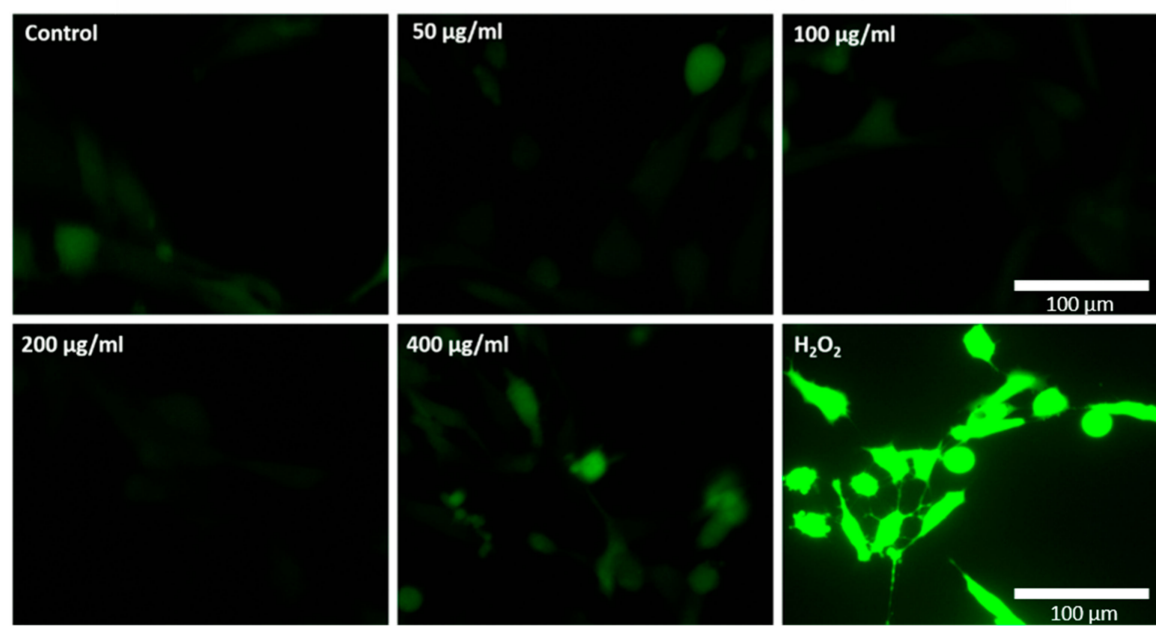

Figure 2. (A) Effect of EGCNPs (24 h exposure) on basal ROS level in HLECs measured by $\mathrm{H}_{2}$ DCFDA fluorescent probe using a plate reader. The asterisk denotes statistical significance $(p<0.05)$ 
from negative control $\left(0 \mu \mathrm{g} \mathrm{mL} \mathrm{m}^{-1}\right), \mathrm{n} \geq 3$ where $\mathrm{n}$ is the number of replicates using ANOVA followed by Dunnett's multiple comparisons test. Error bars are presented as mean \pm standard error of the mean (SEM) (B) Fluorescent microscope images after $\mathrm{H}_{2}$ DCFDA staining of HLECs treated with different EGCNPs concentrations for $24 \mathrm{~h} . \mathrm{H}_{2} \mathrm{O}_{2}(200 \mu \mathrm{M})$ was used as a positive control. Images were taken using a fluorescent microscope (Evos FL) using the same intensity power (20\%) with minimal exposure duration to avoid auto-oxidation of the probe.

\section{EGCNPs Localize in the Mitochondria}

Since the mitochondria are the main source of ROS generation [14], it was necessary to investigate if EGCNPs exert their impact on ROS levels through their localization in the mitochondria. EGCNPs-treated HLECs were harvested and their mitochondria were isolated from the cytosolic fraction by differential centrifugation using a standard mitochondria isolation procedure [23]. The isolated mitochondria were then examined with a scanning electron microscope (SEM) and the presence of cerium was checked for using energy dispersive X-ray spectroscopy (EDX). EDX is a valuable tool enabling the identification of different elements based on their emitted characteristic X-rays after excitation with a high accelerating voltage electron beam [24]. Figure 3A shows an SEM micrograph of the isolated mitochondria (left) and its associated cerium EDX map (right) (the red regions are associated with high cerium characteristic X-ray emissions). The full elemental composition of the scanned map is displayed in Figure $3 \mathrm{~B}$ and the $\mathrm{M} \alpha$ and $\mathrm{L} \alpha$ characteristic $X$-ray emission peaks for cerium were observed at $0.88 \mathrm{KeV}$ and $4.83 \mathrm{KeV}$ respectively. Furthermore, semi-quantitative EDX elemental analysis shows that cerium was the third most abundant element in the mitochondria following carbon and oxygen. These findings clearly confirm that significant localization of EGCNPs in the mitochondria occurs within $24 \mathrm{~h}$ of treatment.

(A)
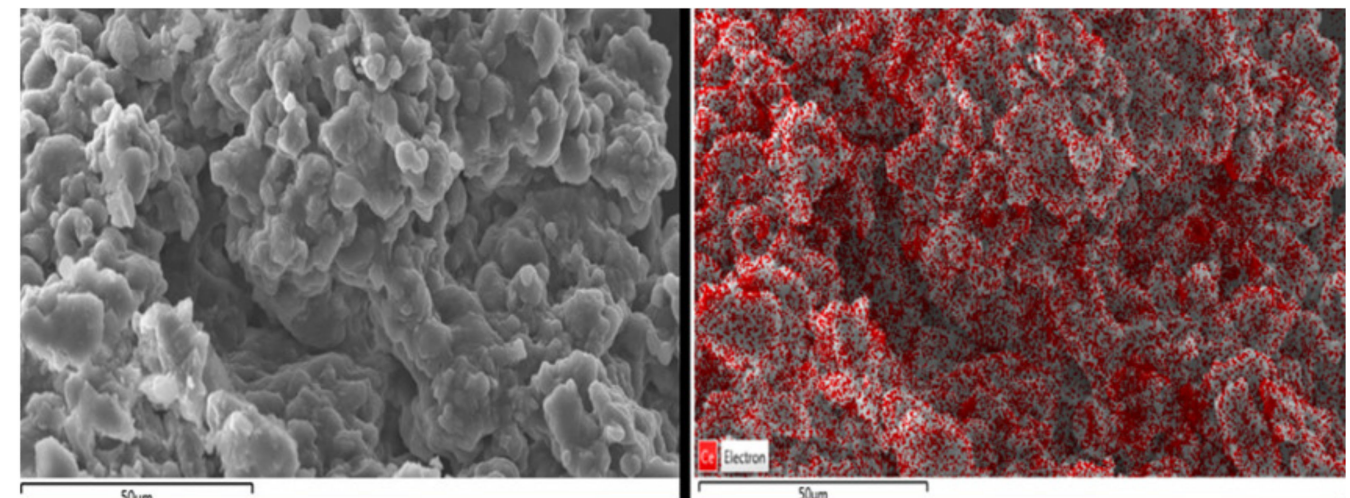

(B)

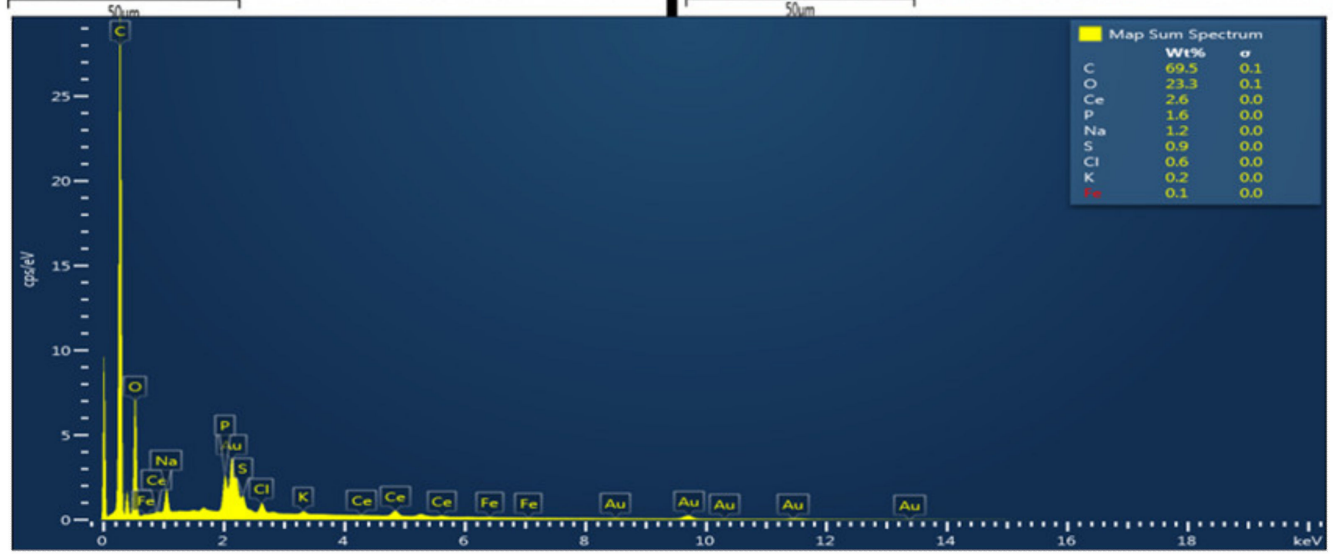

Figure 3. (A) SEM micrograph of the mitochondria isolated from HLECs treated with EGCNPs (left) and its associated cerium EDX mapping (right), (B) EDX spectrum and semiquantitative full elemental 
analysis generated from EDX mapping of the mitochondria. The presence of gold ( $\mathrm{Au})$ is due to sample coating with gold. Scale bar $=50 \mu \mathrm{m}$.

Effect of EGCNPs on the Mitochondrial Network

To examine the effect of EGCNPs on the mitochondrial morphology and network organization, staining with the mitochondria-selective stain (Mitotracker ${ }^{\mathrm{TM}}$ Red CMXRos) was employed. The mitochondria were uniform in shape and organization when treated with EGCNPs concentrations of up to $400 \mu \mathrm{g} \mathrm{mL}^{-1}$ and showed no significant difference from control cells (Figure 4A). The mitochondria were short and rod-shaped with organized localization in the perinuclear region (Figure $4 \mathrm{~B}$ ). $\mathrm{H}_{2} \mathrm{O}_{2}$ (positive control) caused significant mitochondrial aggregation and diffusion of the mitochondrial network was observed.

(A)
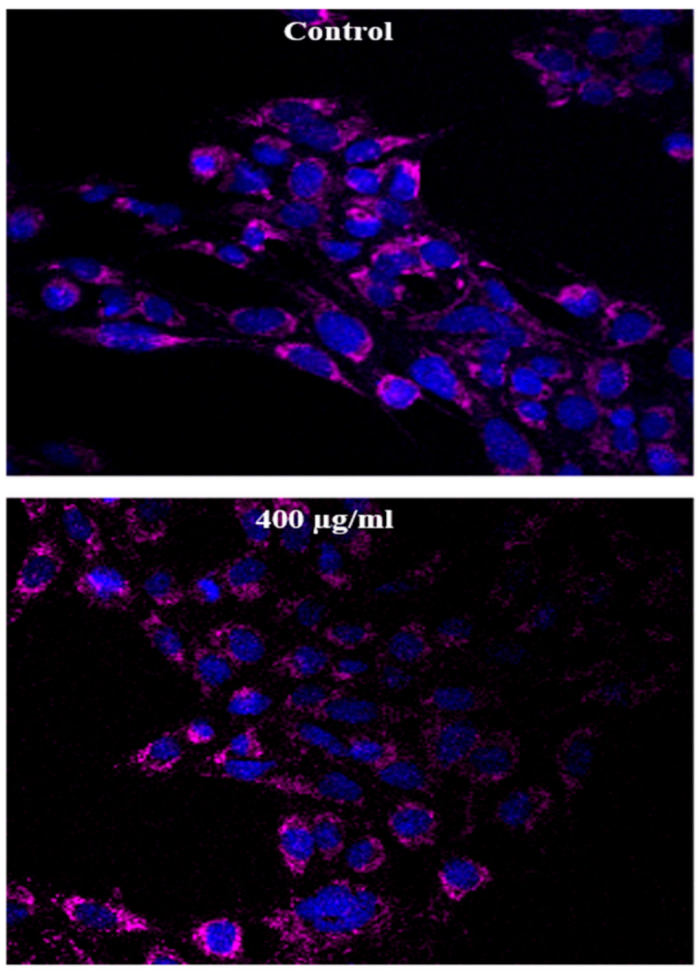

(B)

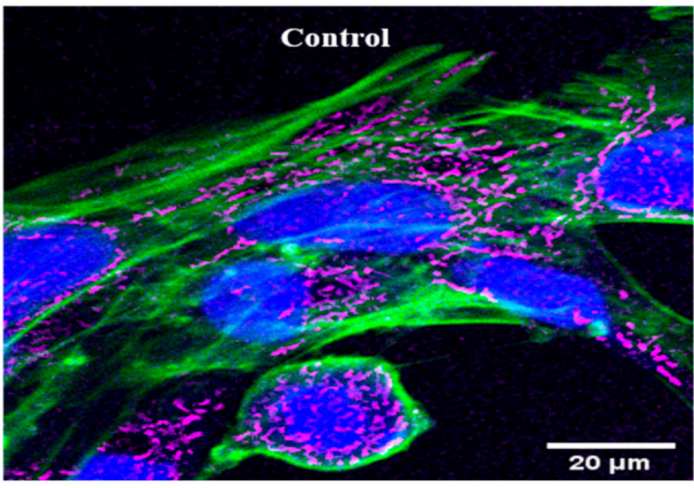

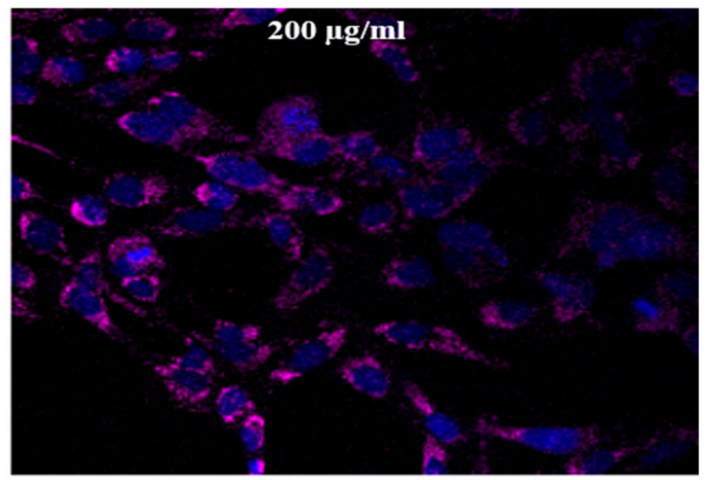
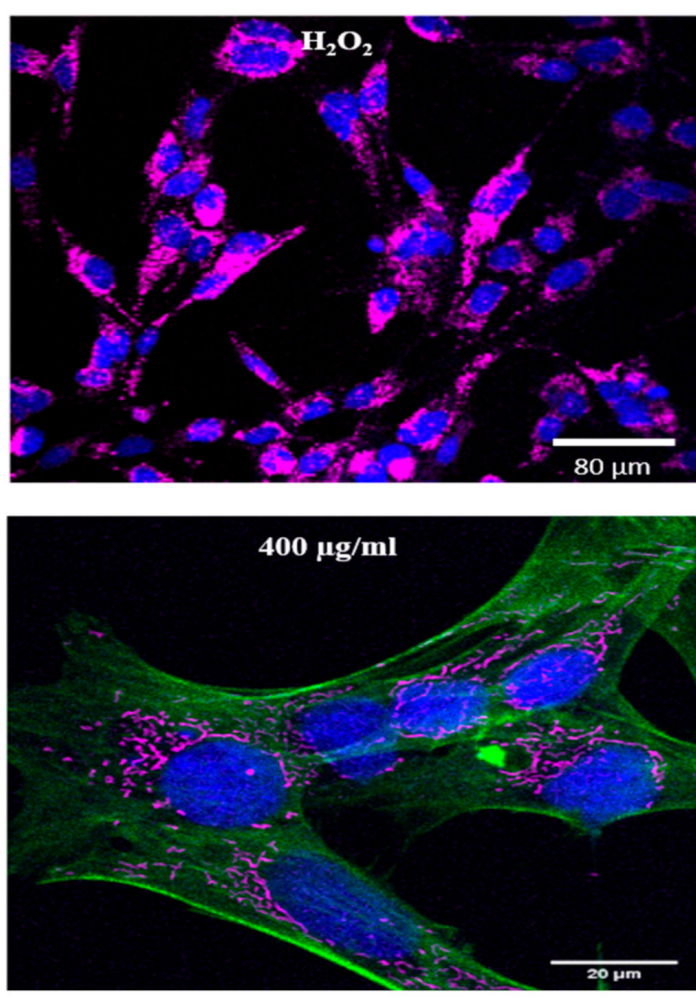

Figure 4. (A) Representative confocal images showing the effect of different EGCNPs concentrations (24 $\mathrm{h}$ exposure) on the mitochondrial morphology and organization (magenta) in HLECs, nuclei are stained with Hoechst 33,342 (blue) (B) High magnification confocal images of the mitochondria counterstained with cytoskeleton selective stain ActinGreen 488 (green) and Hoechst 33,342 (blue). No significant changes from control were observed up to EGCNPs concentrations of $400 \mu \mathrm{g} \mathrm{mL}^{-1}$. $\mathrm{H}_{2} \mathrm{O}_{2}(400 \mu \mathrm{M})$ was used as a positive control which shows significant aggregation of the mitochondria. 


\section{EGCNPS Overdose Disrupts Mitochondrial Membrane Potential ( $\triangle \Psi m)$}

The integrity of the mitochondrial membrane potential is one of the most critical factors in assessing the function of the mitochondria; its depolarization (loss of normal charge distribution on both sides of the membrane) is an indicator for early stage apoptosis [25-27]. JC-1 dye was used to differentiate between healthy and depolarized mitochondria based on the change in the fluorescence of the dye. In healthy mitochondria, the cationic dye accumulates into the negatively charged interior of mitochondria where it forms J-aggregates shifting the fluorescence from green to red. Consequently, decreased red/green ratio is an indicator for mitochondrial membrane depolarization [28]. This ratio is highly accurate as it reports on changes in membrane potential regardless of the shape, size or density of the mitochondria [28]. As shown in Figure 5, EGCNPs concentrations up to $200 \mu \mathrm{gL} \mathrm{m}^{-1} \mathrm{had} \mathrm{no}^{-1}$ significant effect on the $(\Delta \Psi \mathrm{m})$. When the concentration was increased to $400 \mu \mathrm{g} \mathrm{mL} \mathrm{m}^{-1}$, significant depolarization was observed suggesting that early stage apoptosis was taking place. For comparison, two different concentrations of sodium azide $\left(\mathrm{NaN}_{3}\right)$ were used as positive controls since it is known to induce mitochondrial depolarization by blocking complex IV in the mitochondrial electron transport chain [28].

(A)

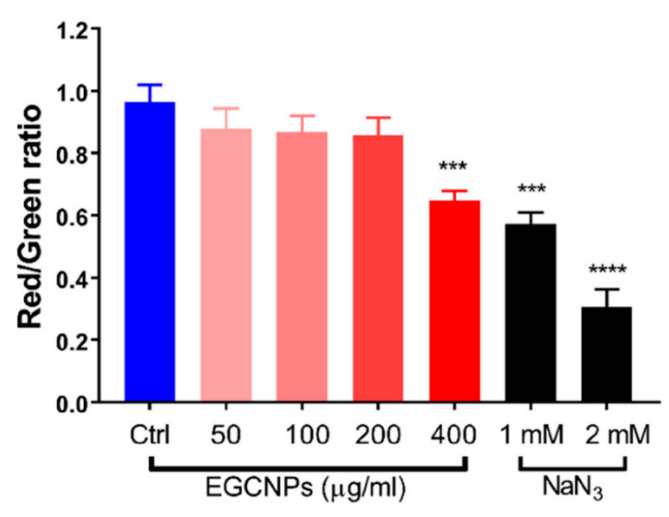

(B)

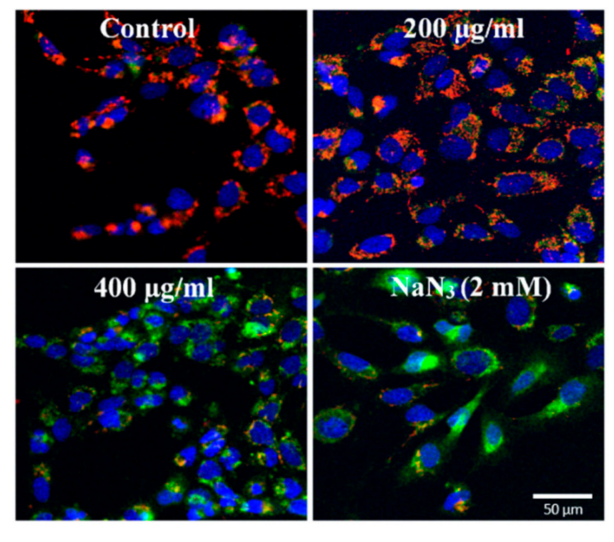

Figure 5. Effect of EGCNPs concentrations on mitochondrial membrane potential $(\Delta \Psi \mathrm{m})$ measured using JC-1 staining. Decrease in red/green ratio indicates depolarization of the mitochondrial membrane. (A) Quantification of red/green ratio from high throughput Incucyte S3 fluorescent images (images available in the SI), (B) Representative high magnification confocal microscopy images with JC-1 staining counterstained with Hoechst 33,342 (blue) showing significant increase in green/red ratio (depolarized $\Delta \Psi \mathrm{m}$ ) at $400 \mu \mathrm{g} \mathrm{mL} \mathrm{m}^{-1}$. Up to $200 \mu \mathrm{g} \mathrm{mL} \mathrm{m}^{-1}$, the red and green had a ratio close to 1 causing them to colocalize. $\mathrm{NaN}_{3}$ was used as a positive control as it is a known disruptor of $\Delta \Psi \mathrm{m}$. Asterisks denote statistical significance $\left.{ }^{* * *}\right) p \leq 0.001$ and $\left({ }^{* * * *}\right) p \leq 0.0001$ from control, $\mathrm{n}=3$, using one-way ANOVA, Dunnett's multiple comparisons. Error bars are presented as mean \pm SEM.

\section{ATP Level (Luciferase Assay)}

The intracellular ATP production is considered a well-accepted differentiator between apoptotic and necrotic cell death [29,30]. Apoptosis is an energy-driven process that requires ATP for its execution such as in the breakdown of macromolecules [30]. When the ATP level drops significantly, it is an indication of the termination of controlled cell death and necrosis starts to take over. The changes in intracellular ATP production upon exposure to different EGCNPs concentrations were measured based on the bioluminescence produced using the highly sensitive luciferin-luciferase assay [29]. Up to $200 \mu \mathrm{g} \mathrm{mL} \mathrm{L}^{-1}$, no significant decline in ATP level was observed as expected from the aforementioned results (Figure 6). Interestingly, no significant change in ATP level was observed at $400 \mu \mathrm{g} \mathrm{mL} \mathrm{mev}^{-1}$ though mitochondrial membrane depolarization does take place at this concentration. The cells were then treated for a longer duration $(48 \mathrm{~h})$, and a significant decrease in ATP production was observed 
at $400 \mu \mathrm{g} \mathrm{mL}^{-1}$ (Figure 6). Another notable finding was the slight but significant increase in ATP levels at 100 and $200 \mu \mathrm{g} \mathrm{mL} L^{-1}$ EGCNP concentrations after $24 \mathrm{~h}$.
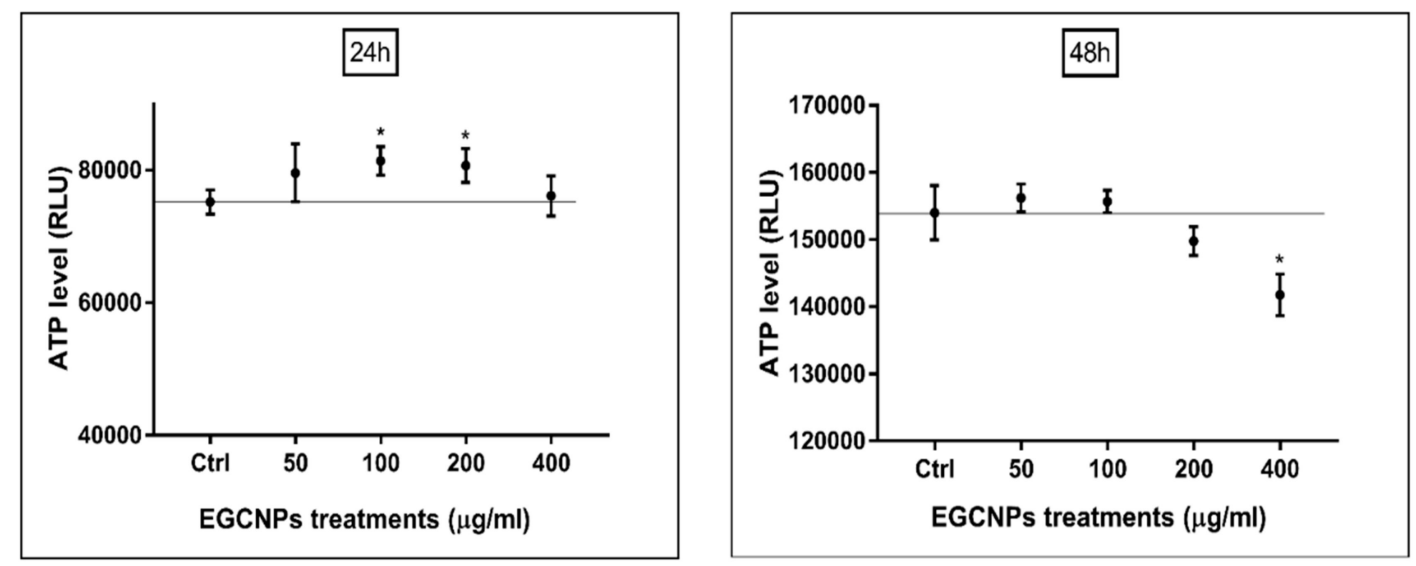

Figure 6. Effect of EGCNPs on ATP production in HLECs measured by luciferin-luciferase bioluminescent assay at $24 \mathrm{~h}$ and $48 \mathrm{~h}$. Asterisks denote statistical significance from control $(p<0.05)$, $\mathrm{n}=3$ using one-way ANOVA. Error bars are presented as mean \pm SEM.

Genotoxicity (pH2AX Immunocytochemistry Assay)

DNA integrity in HLECs is particularly important as its damage could lead to impaired protein synthesis, impaired differentiation and consequently cataract formation [31]. Since DNA is a common target of ROS [32], EGCNP induced genotoxicity was evaluated by detecting DNA double strands breaks (DSBs). As a response to DSBs, the histone protein H2AX is phosphorylated (pH2AX) and this can be detected with immunocytochemistry. The results in Figure 7 show that increased ROS was accompanied with increased DNA damage at $400 \mu \mathrm{g} \mathrm{mL} \mathrm{m}^{-1}$ whereas, at low concentrations, no genotoxicity was observed.

\section{Effect of EGCNPs on Caspase-3,7 Activity}

Activation of caspases is a key indicator of cells irrevocably submitting to apoptotic death [33]. The activation of caspases 3 and 7 (effector caspases in mammals) in HLECs upon EGCNPs treatment was detected over $24 \mathrm{~h}$ by means of live cell imaging using the IncuCyte ${ }^{\circledR}$ Caspase-3/7 Red apoptosis assay reagent. The reagent consists of a red fluorophore $\left(\mathrm{NucView}^{\mathrm{TM}} 633\right)$ attached to an activated caspase recognition motif (DEVD). Upon binding with activated caspases, the motif is cleaved, and the fluorophore that is liberated intercalates with DNA giving red fluorescence proportional to caspase activity that can be quantified over time. Figure 8A shows that EGCNPs do not result in significant caspase activation up to concentrations of $200 \mu \mathrm{g} \mathrm{mL} \mathrm{m}^{-1}$ compared to control cells. Overexposure to EGCNPs $\left(400 \mu \mathrm{g} \mathrm{mL} \mathrm{L}^{-1}\right)$ caused significant caspase activation as early as $12 \mathrm{~h}$ from the treatment commencing. This agrees with the JC-1 data (Figure 5) where loss of membrane potential was observed only at $400 \mu \mathrm{g} \mathrm{mL}^{-1}$. 
(A)

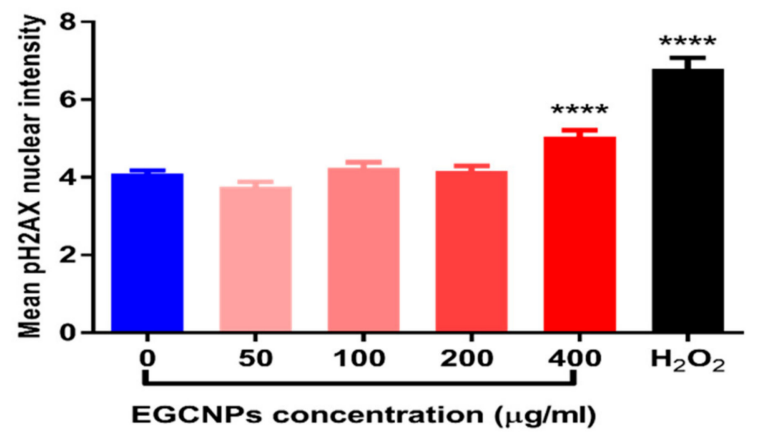

(B)
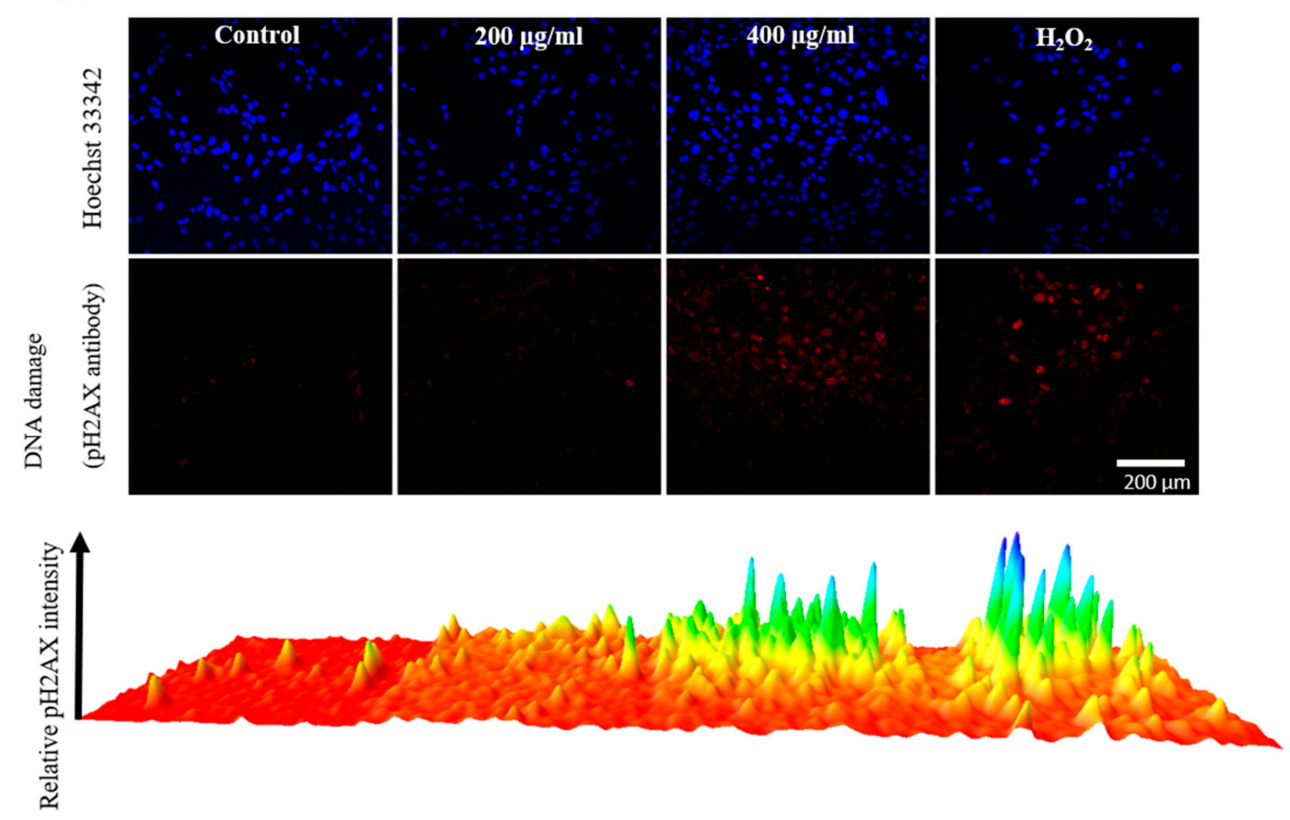

Figure 7. Effect of EGCNPs on DNA damage (genotoxicity) measured by immunocytochemistry thorough detection of $\mathrm{pH} 2 \mathrm{AX}$ mean intensity. (A) quantification of $\mathrm{pH} 2 \mathrm{AX}$ fluorescence intensity (only pH2AX signal inside nuclei perimeters) within at least 500 individual nuclei obtained from 4 independent experiments. (B) representative confocal images and 3D surface plotting of relative $\mathrm{pH} 2 \mathrm{AX}$ intensity (red). Asterisks denote statistical significance from control $(p<0.05)$ using one-way ANOVA, Dunnett's multiple comparisons. Error bars are presented as mean \pm SEM. A schematic showing DNA damage quantification steps is shown in the Supplementary Information.

\section{Annexin V/Cytotox Red Assay}

To confirm whether cells undergo apoptosis rather than necrosis at EGCNP concentration of $400 \mu \mathrm{g} \mathrm{mL} \mathrm{m}^{-1}$, the cells were double stained with annexin $\mathrm{V}$ green/Cytotox Red and observed by means of live cell imaging using Incucyte S3 live imaging system. Apoptotic cells only show annexin V labelling (green) while late apoptotic or necrotic cells are double labelled with both stains. Figure 8B shows that the $400 \mu \mathrm{g} \mathrm{mL} \mathrm{m}^{-1}$ concentration caused a significant increase in cells labelled with annexin $\mathrm{V}$, when compared to negative control after treatment durations of $6 \mathrm{~h}, 12$ hand $24 \mathrm{~h}$. No significant change was found in the number of necrotic cells (labelled with Cytotox Red) over the same treatment durations (Figure 8C). These findings indicate that apoptosis is the main mechanism of cell death in HLECs with acute overexposure to EGCNPs. 


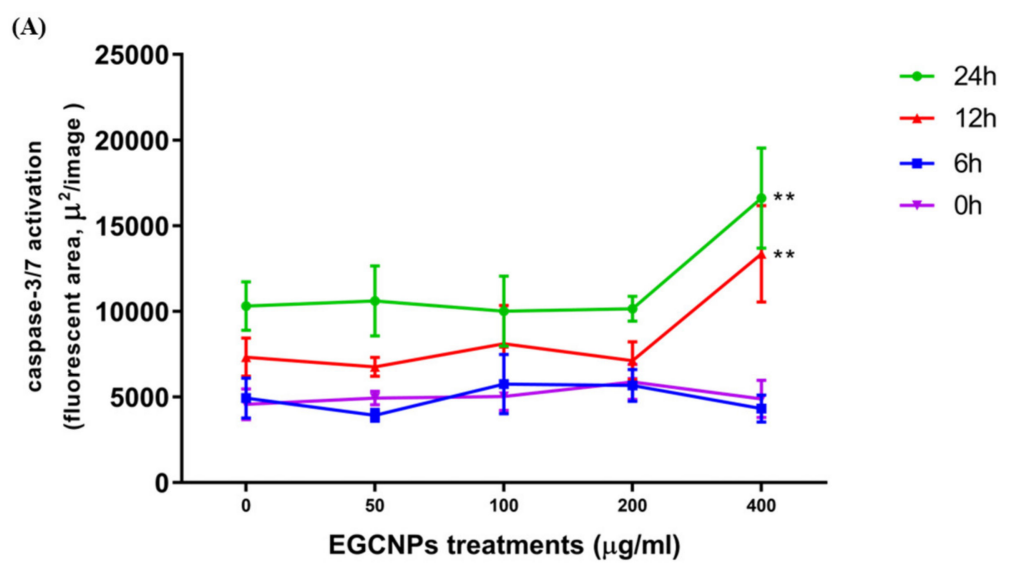

(B)

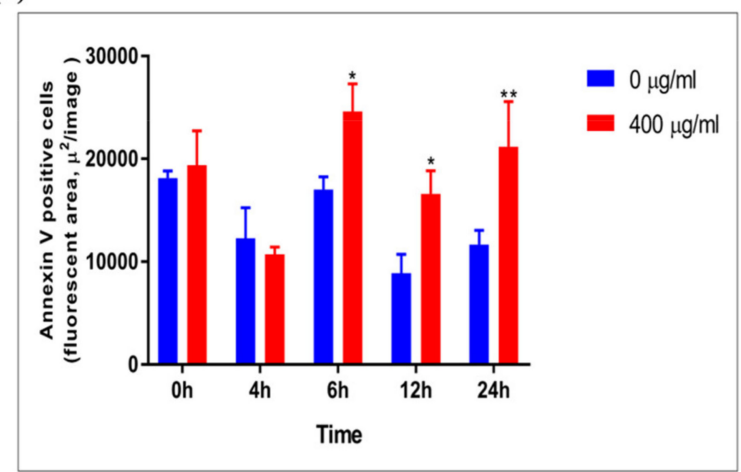

(C)

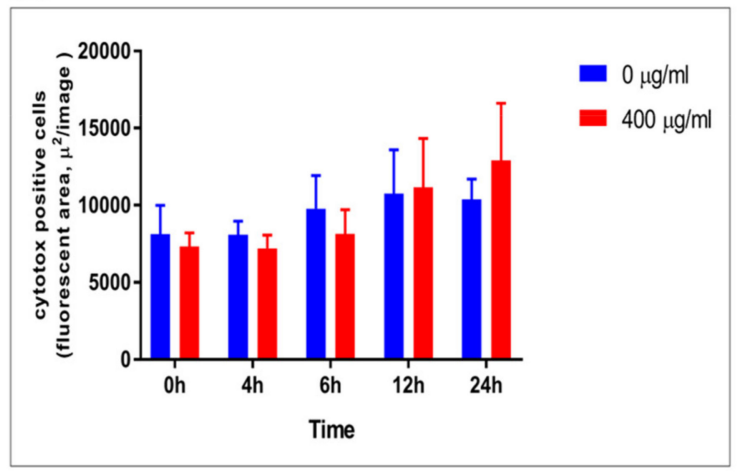

Figure 8. Effect of different EGCNPs concentrations on (A) caspase-3,7 activity, (B) Annexin V binding after $24 \mathrm{~h},(\mathrm{C})$ Cytotox Red staining after $24 \mathrm{~h}$ in HLECs. No significant caspase activation was observed up to $200 \mu \mathrm{g} \mathrm{mL} \mathrm{m}^{-1}$. At $400 \mu \mathrm{g} \mathrm{mL} \mathrm{m}^{-1}$, significant caspase activity was observed after $12 \mathrm{~h}$ of treatment. Asterisks $\left.{ }^{*}\right) \mathrm{p} \leq 0.05$ and $\left(^{* *}\right) \mathrm{p} \leq 0.01$ denote statistical significance from control in same time group, $\mathrm{n}=4$ where $\mathrm{n}$ is the number of replicates, using two-way ANOVA. Error bars are presented as mean \pm standard error of the mean (SEM). Representative images that were used for quantification are available in the Supplementary Information.

\section{Discussion}

Cerium oxide nanoparticles have shown antioxidant activities in different mammalian cell lines because of their ability to scavenge for different ROS in an enzyme-mimetic fashion $[4,17,34]$. They have shown promise in the treatment of many ocular diseases such as retinal injury [17]. Additionally, we have recently reported that a novel ultra-small $(4 \mathrm{~nm})$ and well characterized monodisperse nanoceria formulation coated with modified ethylene glycol can protect HLECs from oxidative stress induced by $\mathrm{H}_{2} \mathrm{O}_{2}$ when used at concentrations as low as $50 \mu \mathrm{g} \mathrm{mL} \mathrm{L}^{-1}$, indicating that nanoceria may have potential as an anticataract treatment [20]. Interestingly, it was found that HLECs can proliferate normally with the same rate when treated with EGCNPs concentrations up to $400 \mu \mathrm{g} \mathrm{mL}^{-1}$ for three days. However, a significant decrease in viability measured by MTT assay was observed at $24 \mathrm{~h}$ suggesting that the mitochondria may be affected with nanoceria treatment since the MTT assay assesses the viability based on the activity of mitochondrial succinate dehydrogenase [35]. Consequently, in this study, the aim was to elucidate the biological consequences of the interaction between EGCNPs at $400 \mu \mathrm{g} \mathrm{mL} \mathrm{m}^{-1}$ and mitochondria in HLECs. Concentrations above $400 \mu \mathrm{g} \mathrm{mL} \mathrm{m}^{-1}$ caused a marked decrease in proliferation and cell membrane damage (necrosis) and were not subject to further study.

The overproduction of ROS is involved in the etiology and pathogenesis of many diseases and disorders such as Alzheimer's, Parkinson's, diabetes, and cataract. The identification and effects of new drugs on the redox state of a target cell line/cell/tissue is essential [36-39]. In this study, the basal ROS level in HLECs was not affected at low concentrations of EGCNPs. However, a significant 
increase in basal ROS was seen when the concentration was increased to $400 \mu \mathrm{g} \mathrm{mL}{ }^{-1}$ (Figure 2). This shows that even though EGCNPs possess antioxidant and ROS scavenging properties, short-term overexposure can elevate ROS levels. This increase in ROS levels is likely to have been caused by Fenton like reactions where reduced metal ions (e.g., $\mathrm{Ce}^{3+}$ ) react with cellular hydrogen peroxide $\left(\mathrm{H}_{2} \mathrm{O}_{2}\right)$, producing hydroxyl radicals $(\mathrm{HO} \bullet)$ that are highly toxic to biomolecules [32]. It was previously shown that EGCNPs had surface trivalent cerium and hence the progression of a Fenton-like reaction is expected to progress as reported in the literature [40]. It is of significant importance that therapeutic doses of EGCNPs $\left(<200 \mu \mathrm{g} \mathrm{mL}{ }^{-1}\right)$ do not alter the basal ROS level which is needed to maintain normal metabolic functions and signaling pathways [22]. Our previous work showed that EGCNPs used at $50 \mu \mathrm{g} \mathrm{mL}^{-1}$, scavenge for ROS induced by $\mathrm{H}_{2} \mathrm{O}_{2}$ in HLECs. Considering the results shown here, this suggests that at low concentrations, EGCNPs only exert their ROS lowering capability in the presence of external ROS stimuli without diminishing the cellular benefits of basal ROS.

Since the mitochondria are the major sites for ROS generation [14], it was speculated that their properties and function would be altered with acute exposure to EGCNPs. EGCNPs have been shown to localize mainly in the cytoplasm of HLECs, however, organelle-specific localization was not identified [20]. In this study, the mitochondrial localization of EGCNPs was confirmed by examining isolated mitochondria from EGCNPs-treated HLECs using SEM-EDX (Figure 3). By using this technique, it was feasible to avoid surface functionalization with fluorescent markers; a common practice in the literature to track the nanoparticles that changes the surface properties and in turn could affect the uptake behavior of nanoparticles [41]. The mitochondrial localization of EGCNPs is likely to be caused by the strong positive zeta potential value that EGCNPs carry $(+44 \mathrm{mV})$ making the negatively charged interior of the mitochondria an ideal target [36]. This finding is interesting since it is known from our previous investigation that protein coronae are adsorbed on the surface of EGCNPs making the zeta potential value slightly negative $(-9.7 \mathrm{mV})$ in cell culture media containing fetal bovine serum. Nonetheless, the coronae do not appear to prevent the nanoparticles from entering the mitochondria. The zeta potential is known to play a significant role in subcellular localization of nanoceria which affects both the toxicity and activity profile [42]. It has previously been shown that targeting nanoceria specifically to mitochondria by surface functionalization with the mitochondrial-targeting cationic ligand (triphenylphosphonium, TPP), suppresses oxidative stress-induced neuronal death in mice [36]. Our findings indicate that this specific functionalization is not required for mitochondrial uptake in HLECs. Following the confirmation of mitochondrial uptake of EGCNPs, the effect of such uptake on the morphology and network organization of the mitochondria was studied using confocal microscopy and was found to be similar up to $400 \mu \mathrm{g} \mathrm{mL}^{-1}$ Figure 4). This suggested that at the higher concentration $\left(400 \mu \mathrm{g} \mathrm{mL}^{-1}\right)$ the cells could be undergoing early stage apoptosis, in which the shape of the mitochondria remains intact $[25,30]$. Hence, some of the key apoptotic hallmarks were further investigated.

One of the key indicators of early stage apoptosis is the loss of mitochondrial membrane potential where membrane depolarization and formation of mitochondrial membrane transition pores allow the release of mitochondrial intermembrane space enzymes (e.g., cytochrome c) that activate the caspase cascade initiating apoptosis [26,33]. Indeed, significant mitochondrial membrane depolarization at the higher dose of EGCNPs was observed and this indicated that apoptosis was taking place (Figure 5). To support these findings, the ATP level in EGCNPs treated HLECs was measured. Since apoptosis is an energy-dependent process, it was expected that the ATP level should remain relatively the same during the initial stages of apoptosis. Various studies have shown that ATP levels do not change during the initial stages of apoptosis [29]. This was the case in EGCNPs-treated HLECs as the $400 \mu \mathrm{g} \mathrm{mL}^{-1}$ concentration showed no significant difference in ATP level from control cells or those treated with lower concentrations of nanoceria (Figure 5). This could be explained by the fact that cells require ATP in order to initiate the controlled apoptotic cell death through various ATP-dependent steps such as caspase activation, nuclear condensation and apoptotic body formation [29]. To further test this assumption, the cells were treated for a longer duration $(48 \mathrm{~h})$, and indeed a small but significant decrease, in ATP at $400 \mu \mathrm{g} \mathrm{mL}^{-1}$ was observed, indicating the termination of apoptosis in some of 
the cells with concomitant ATP depletion. It is noteworthy that at $24 \mathrm{~h}$, safe EGCNPs concentrations $\left(\leq 200 \mu \mathrm{g} \mathrm{mL}^{-1}\right)$ caused a slight increase in ATP levels. One possible reason is that the uptake of EGCNPs may have proceeded through energy-dependent clathrin-mediated and caveolae-mediated endocytic pathways, which have been reported as the main uptake mechanism of nanoceria in many cell lines [41-43].

DNA integrity is of particular interest in HLECs since the cells are continually synthesizing lens proteins (crystallins), and hence damage could lead to disrupted protein expression and eventually lead to cataract formation [44]. It was shown before that nanoceria coated with 3-phosphonopropionic acid have no adverse effect on DNA health when exposed to a concentration of $10 \mu \mathrm{g} \mathrm{mL}^{-1}$ for $24 \mathrm{~h}$ [45]. It was demonstrated that EGCNPs can be tolerated at a 20 -fold higher concentration $\left(200 \mu \mathrm{g} \mathrm{mL}{ }^{-1}\right)$ for the same treatment duration. However, a dose of $400 \mu \mathrm{g} \mathrm{mL}{ }^{-1}$ caused significant DNA double strand breaks (as shown in Figure 7). DNA damage is likely to be caused by increased ROS that attack the DNA, causing double strand breaks. It was reported that some nuclear uptake of EGCNPs take place at therapeutic concentrations (less $200 \mu \mathrm{g} \mathrm{mL}^{-1}$ ) [20]. This nuclear uptake is likely to have been increased at $400 \mu \mathrm{g} \mathrm{mL}^{-1}$ causing EGCNPs to aggregate inside the nuclei promoting genotoxicity [16]. Even though some nanoparticles have poor permeability into the nuclei, their entry is inevitable during mitosis where the nuclear membrane is broken as the cells prepare for division [46]. As such, higher doses of EGCNPs will provide more opportunity for increased localization and possibly aggregation into the nuclei. The aforementioned events are likely to have led to the activation of caspases at $\left(400 \mu \mathrm{g} \mathrm{mL}^{-1}\right)$ which are the key causes of apoptosis (Figure 8) [33]. Additionally, annexin V/Cytotox Red assay conclusively demonstrated that apoptosis is the main driver for cell death, where an increase in annexin $\mathrm{V}$ binding was observed without concomitant increase necrosis-specific Cytotox Red labelling (Figure 8). Together these results demonstrate that the main mechanism of cerium oxide toxicity in HLECs proceeds through a mitochondrial apoptotic pathway mediated by elevated ROS and DNA damage.

The toxicity of nanoceria has been studied in vitro using a range of cell lines (reviewed in Gagnon and Fromm, 2015) but the data are not comparable given the varying characteristics of nanoceria used including the shape, size, colloidal stability, zeta potential, surface valence, surface functionality and the range of nanoceria fabrication methods. There are still inconsistencies in the literature regarding the mechanism of nanoceria toxicity [13]. Our results show, in a dose-dependent manner, the toxicity mechanism of well characterized nanoceria (EGCNPs) in human lens epithelium. To conclude, when considering nanoceria toxicity, and given their redox active characteristics, emphasis must be on the evaluation of the mitochondrial functionality as an early indicator for cell health as it can reveal significant effects that can be easily overlooked in short-term proliferation and standard toxicological studies.

\section{Materials and Methods}

\section{Synthesis of Ethylene Glycol-Coated Cerium Oxide Nanoparticles (EGCNPs)}

Cerium oxide nanoparticles coated with ethylene glycol and ethylene glycol mono- and diacetates (EGCNPs) were synthesized in aqueous conditions using the ammonia precipitation method as reported previously [20].

\section{Cell Culture}

Human lens epithelial cells (HLECs) (B3, ATCC ${ }^{\circledR}$ CRL11421 ${ }^{\mathrm{TM}}$ ) were cultured in Eagle's minimum essential media (EMEM) (ATCC ${ }^{\circledR}$ 30-2003) supplemented with fetal bovine serum (20\%, Scientific Lab Supplies), penicillin (100 units/mL, Sigma Aldrich) and streptomycin (0.1 mg/mL, Sigma Aldrich). The cells were incubated at $37^{\circ} \mathrm{C}$ and $5 \% \mathrm{CO}_{2}$ in a humidified environment $(95 \% \mathrm{RH})$. The experiments were carried out on HLECs in the log growth phase. 


\section{Basal ROS Level}

$\mathrm{H}_{2}$ DCFDA probe (2',7'-dichlorodihydrofluorescein diacetate, D399, ThermoFisher) was employed to measure basal ROS levels as previously reported [20]. Briefly, HLECs were seeded in 96-well plates in complete EMEM (5000 cells/well) and allowed to recover for $24 \mathrm{~h}$. The media were then removed and replaced with fresh media containing different EGCNPs concentrations $(0,50,100,200$, and $400 \mu \mathrm{g} \mathrm{mL}^{-1}$ ) for $24 \mathrm{~h}$. A maximum of $400 \mu \mathrm{g} \mathrm{mL}^{-1}$ was previously reported as the highest concentration beyond which a marked decrease in proliferation is observed [20]. $\mathrm{H}_{2} \mathrm{O}_{2}(200 \mu \mathrm{M}$, Sigma Aldrich) was used as a positive control. After the treatment period, the media were discarded, cells were washed once with pre-warmed PBS (ATCC ${ }^{\circledR} 30-2200^{\mathrm{TM}}$ ) and incubated with H2DCFDA solution (10 $\mu \mathrm{M}$ in PBS) for $30 \mathrm{~min}$ at $37^{\circ} \mathrm{C}$. H2DCFDA solution was then discarded, cell washed with pre-warmed PBS and fresh PBS $(200 \mu \mathrm{L})$ was added to each well. DCF fluorescence intensity was measured using a microplate reader (FLUOstar Omega, BMG LABTECH, Ortenberg, Germany) at excitation/emission of $485 / 520 \mathrm{~nm}$. Correcting the fluorescence values was performed before analysis by subtracting the fluorescence of unstained cells from all other values. No fluorescence was observed for cell-free H2DCFDA/PBS and H2DCFDA/PBS/EGCNPs mixtures.

\section{EGCNPs Mitochondrial Uptake and Localization (SEM-EDX Studies)}

HLECs were grown in five T175 flasks until they reached approximately $80 \%$ confluence. The cells were then treated with EGCNPs $\left(400 \mu \mathrm{g} \mathrm{mL}{ }^{-1}\right)$ for $24 \mathrm{~h}$ and subsequently harvested, pelleted and washed once with full media and once with PBS. The mitochondria were then isolated from the pellet using the Mitochondria Isolation Kit for Cultured Cells (89874, ThermoFisher, Paisley, UK) in accordance with the supplier's instructions. The isolated mitochondria were washed once with PBS, fixed with paraformaldehyde ( $4 \%, 5 \mathrm{~min}$ ) and dried in pure ethanol (5 $\mathrm{min})$. The mitochondria were placed on a SEM aluminum stub covered with a carbon tape and the specimens were coated with a gold layer (5 nm) using a sputter coater (Q150R ES, Quorum Technologies Ltd, East Sussex, UK). The specimens were examined using a scanning electron microscope equipped with an EDX detector (JEOL, JSM-7100f, Tokyo, Japan). EDX spectra and mapping were acquired and processed using Aztec software (v.2011, Oxford Instruments, Abingdon, UK).

\section{Mitochondrial Morphology (Confocal Studies)}

HLECs were seeded (5000 cells/well) in black 96-well plates with clear flat bottom (Falcon ${ }^{\circledR} 353219$, Corning, New York, US) and left to establish for $24 \mathrm{~h}$. The following day, the media were discarded, and the cells were treated with EGCNPs-containing media $\left(0,50,100,200\right.$ and $\left.400 \mu \mathrm{g} \mathrm{mL}{ }^{-1}\right)$ for $24 \mathrm{~h}$. After the treatment period, the media were removed, and the cells were washed once with pre-warmed PBS. The cells were then incubated with full media containing MitoTracker ${ }^{\mathrm{TM}}$ Red CMXRos (200 nM, ThermoFisher, Paisley, UK) for $20 \mathrm{~min}$ at $37^{\circ} \mathrm{C}$. After staining, the cells were washed once with pre-warmed PBS, fixed in pre-warmed paraformaldehyde solution (4\% in PBS) for $10 \mathrm{~min}$ at room temperature and permeabilized by incubating in ice-cold acetone for $5 \mathrm{~min}$. The cells were then counterstained by incubating in PBS containing Hoechst 33,342 $(2 \mu \mathrm{g} / \mathrm{mL}$, ThermoFisher, Paisley, UK) for $20 \mathrm{~min}$ at room temperature. Imaging was carried out using a confocal laser scanning microscope (Leica, Wetzlar, Germany) using the following settings: sequential scanning, 20x dry objective, ex/em: Mitotracker: 543/599 nm, Hoechst: 405/461 nm.

\section{Mitochondrial Membrane Potential (JC-1 Staining)}

JC-1 probe (Abcam) was employed for mitochondrial membrane potential measurements. HLECs were seeded, established and treated with different EGCNPs concentrations (0, 50, 100, 200 and $400 \mu \mathrm{g} \mathrm{mL}^{-1}$ ) as before and sodium azide (1 and $2 \mathrm{mM}$, Sigma Aldrich, Gillingham, UK) was used as a positive control. After the treatment period, the media were removed, and cells incubated with JC-1 probe in complete media $(10 \mu \mathrm{M})$ for $30 \mathrm{~min}$ at $37^{\circ} \mathrm{C}$ in dark conditions. The staining 
solution was removed, cells washed with PBS and replaced with phenol red-free complete media. The wells were then imaged using Incucyte S3 high throughput imaging system using the green and red channels ( 5 wells per treatment condition, three images per well) and quantification of the red/green ratio was calculated using the integrated software by dividing the fluorescence area of the red channel over the fluorescence area of the green channel. Other software (e.g., ImageJ (version 2, NIH, Maryland, US) can be employed for such calculations by thresholding the red and green fluorescence and subsequently calculating their corresponding areas. The experiment was run in triplicate. Qualitative high magnification images were acquired using a confocal microscope after nuclear staining with Hoechst 33342. The excitations/emission settings were as follows: Hoechst $33,342(405 / 461 \mathrm{~nm})$, JC-1 green monomers (488/530 nm), JC-1 red aggregates (543/590 nm).

\section{ATP Quantification (Luciferase Assay)}

The quantification of cellular ATP was carried out using the luminescent luciferase assay (CellTiter-Glo, Promega) in accordance with the supplier's instructions. Briefly, HLECs were established in 96-well plates as before and treated with different EGCNPs concentrations for $24 \mathrm{~h}$ and $48 \mathrm{~h}$. After the treatment period, the media were removed and replaced with fresh media. An equal volume of CellTiter-Glo reagent was added to each well to lyse the cells and release a luminescent signal proportional to the amount of ATP present. The plate was placed on an orbital shaker for $2 \mathrm{~min}$ and then incubated in the dark at room temperature for $10 \mathrm{~min}$ to stabilize the signal. The luminescent signal was read using a luminometer (Infinite ${ }^{\circledR} 200$ PRO, TECAN, Männedorf, Switzerland).

\section{Genotoxicity (Immunocytochemistry)}

The DNA damage was evaluated using the HCS DNA kit (ThermoFisher) according to the supplier's instructions. Briefly, HLECs were seeded in a black 96-well plate, established and treated for $24 \mathrm{~h}$ with different EGCNPs concentrations $\left(0,50,100,200\right.$ and $\left.400 \mu \mathrm{g} \mathrm{mL}{ }^{-1}\right)$ as before. After the treatment period, the media was removed, the cells were fixed in paraformaldehyde solution $(4 \%, 10 \mathrm{~min})$, rinsed with PBS, and permeabilized in 0.2\% Triton-X-100 (15 min). The cells were washed with PBS and then incubated in a blocking buffer (bovine serum albumin in PBS, $1 \%$ ) for $1 \mathrm{~h}$ at room temperature. The blocking buffer was removed, and the cells were incubated with the primary antibody solution (pH2AX mouse monoclonal antibody) for $1 \mathrm{~h}$. The primary antibody solution was then removed, and the cells were washed three times with PBS and incubated with the secondary antibody/nuclear stain solution (Alexa Fluor 555 goat anti-mouse IgG/Hoechst 33342) for $1 \mathrm{~h}$. The secondary antibody solution was then removed, the cells were washed three times with PBS, and replaced with fresh PBS before proceeding to imaging. Imaging was carried out using a confocal laser scanning microscope using the following settings (sequential scanning ex/em: pH2AX: 543/565 nm, Hoechst: 405/461 nm). For data analysis, Hoechst staining was used for nuclear segmentation and the DNA damage was measured by the increase in the fluorescence of $\mathrm{pH} 2 \mathrm{AX}$ signal in the region defined as the nuclei. The experiment was repeated four times and at least 100 nuclei were analyzed in each replicate.

\section{Caspase-3,7 Assay (Live Cell Imaging)}

HLECs were seeded in 96-well plates (5000 cells per well) and left to establish for $24 \mathrm{~h}$. The cells were then treated with different EGCNPs concentration $\left(0,50,100,200\right.$ and $\left.400 \mu \mathrm{g} \mathrm{mL}^{-1}\right)$ in supplemented EMEM in presence of IncuCyte ${ }^{\circledR}$ Caspase- $3 / 7$ Red Apoptosis Assay Reagent $(0.5 \mu \mathrm{M}$, excitation/emission $630 / 650 \mathrm{~nm}$ ). The cells were imaged every $2 \mathrm{~h}$ for $24 \mathrm{~h}$ using the Incucyte $\mathrm{S} 3$ live cell imaging system (Essen BioScience, Welwyn Garden City, UK) fitted inside an incubator $\left(5 \% \mathrm{CO}_{2}, 37^{\circ} \mathrm{C}\right)$. Three fields of view were imaged per well using the $20 \times$ objective. Images were then analyzed, and caspase activity was expressed as the area of red fluorescent caspase signal per image. The experiment was performed four times. 


\section{Annexin V/Cytotox Red Assay (Live Cell Imaging)}

The assay was performed on the Incucyte S3 live cell imaging system as described above but in the presence of double staining IncuCyte ${ }^{\circledR}$ Annexin V Green Reagent/IncuCyte ${ }^{\mathrm{TM}}$ Cytotox Red Reagent (250 nM). Excitation/emission maxima for Annexin V and Cytotox Red are 490/515 nm and $612 / 631 \mathrm{~nm}$ respectively.

\section{Conclusions}

The antioxidant properties of nanoceria are dose dependent with oxidative actions triggered if the concentration is increased beyond a certain threshold. Nanoceria manifest no cytotoxic or genotoxic effects in human lens epithelial cells when concentrations are up to $200 \mu \mathrm{g} \mathrm{mL}{ }^{-1}$. At $400 \mu \mathrm{g} \mathrm{m}^{-1}$, these nanoparticles induced ROS generation which mediated cellular apoptosis driven by the mitochondrial apoptotic pathway. Potential biomedical applications need to take this threshold into consideration. Further work is needed to determine thresholds for other cell and tissue types.

Supplementary Materials: The following are available online at http://www.mdpi.com/1420-3049/25/3/441/s1, Figure S1: Representative Incucyte images used for the quantification of JC-1 red/green ratio in HLECs after treatment with different EGCNPs concentrations, Figure S2: Representative Incucyte images used for measurement of caspase-3,7 activity in HLECs after treatment with different EGCNPs concentrations $\left(0-400 \mu \mathrm{g} \mathrm{mL}{ }^{-1}\right)$ for $24 \mathrm{~h}$, Figure S3: Representative Incucyte images of Annexin V green/Cytotox Red staining in HLECs comparing control and EGCNPs treated cells ( $24 \mathrm{~h}$ ), Figure S4: Schematic representation of the steps employed for the quantification of DNA damage.

Author Contributions: All authors have read and agree to the published version of the manuscript. All authors contributed to experimental design, B.H. conducted the experiments, all authors contributed to analysis of results and writing the manuscript.

Funding: This research has been funded by Nottingham Trent University VC studentship scheme.

Acknowledgments: The authors would like to thank Charlotte Howard for her valuable insights on the Mitotracker and JC-1 mitochondrial studies.

Conflicts of Interest: The authors declare no conflict of interest.

\section{References}

1. De Matteis, V.; Cascione, M.; Toma, C.C.; Leporatti, S. Morphomechanical and organelle perturbation induced by silver nanoparticle exposure. J. Nanoparticle Res. 2018, 20, 73. [CrossRef]

2. Pandurangan, M.; Kim, D.H. In vitro toxicity of zinc oxide nanoparticles: A review. J. Nanoparticle Res. 2015, 17, 158. [CrossRef]

3. Manke, A.; Wang, L.; Rojanasakul, Y. Mechanisms of nanoparticle-induced oxidative stress and toxicity. Biomed. Res. Int. 2013, 2013. [CrossRef] [PubMed]

4. Xu, C.; Qu, X. Cerium oxide nanoparticle: A remarkably versatile rare earth nanomaterial for biological applications. NPG Asia Mater. 2014, 6, e90. [CrossRef]

5. Li, C.; Shi, X.; Shen, Q.; Guo, C.; Hou, Z.; Zhang, J. Hot Topics and Challenges of Regenerative Nanoceria in Application of Antioxidant Therapy. J. Nanomater. 2018, 2018, 1-12. [CrossRef]

6. Alpaslan, E.; Yazici, H.; Golshan, N.H.; Ziemer, K.S.; Webster, T.J. PH-Dependent Activity of Dextran-Coated Cerium Oxide Nanoparticles on Prohibiting Osteosarcoma Cell Proliferation. ACS Biomater. Sci. Eng. 2015, 1, 1096-1103. [CrossRef]

7. Von Montfort, C.; Alili, L.; Teuber-Hanselmann, S.; Brenneisen, P. Redox-active cerium oxide nanoparticles protect human dermal fibroblasts from PQ-induced damage. Redox Biol. 2015, 4, 1-5. [CrossRef]

8. He, L.; Su, Y.; Lanhong, J.; Shi, S. Recent advances of cerium oxide nanoparticles in synthesis, luminescence and biomedical studies: A review. J. Rare Earths 2015, 33, 791-799. [CrossRef]

9. $\quad$ Pirmohamed, T.; Dowding, J.M.; Singh, S.; Wasserman, B.; Heckert, E.; Karakoti, A.S.; King, J.E.S.; Seal, S.; Self, W.T. Nanoceria exhibit redox state-dependent catalase mimetic activity. Chem. Commun. 2010, 46, 2736-2738. [CrossRef]

10. Korsvik, C.; Patil, S.; Seal, S.; Self, W.T. Superoxide dismutase mimetic properties exhibited by vacancy engineered ceria nanoparticles. Chem. Commun. 2007, 10, 1056-1058. [CrossRef] 
11. Gantt, B.; Hoque, S.; Fahey, K.M.; Willis, R.D.; Delgado-Saborit, J.M.; Harrison, R.M.; Zhang, K.M.; Jefferson, D.A.; Kalberer, M.; Bunker, K.L.; et al. Factors affecting the ambient physicochemical properties of cerium-containing particles generated by nanoparticle diesel fuel additive use. Aerosol Sci. Technol. 2015, 49, 371-380. [CrossRef]

12. Hussain, S.; Al-Nsour, F.; Rice, A.B.; Marshburn, J.; Yingling, B.; Ji, Z.; Zink, J.I.; Walker, N.J.; Garantziotis, S. Cerium dioxide nanoparticles induce apoptosis and autophagy in human peripheral blood monocytes. ACS Nano 2012, 6, 5820-5829. [CrossRef] [PubMed]

13. Yokel, R.A.; Hussain, S.; Garantziotis, S.; Demokritou, P.; Castranova, V.; Cassee, F.R. The yin: An adverse health perspective of nanoceria: Uptake, distribution, accumulation, and mechanisms of its toxicity. Environ. Sci. Nano 2014, 1, 406-428. [CrossRef] [PubMed]

14. Fu, P.P.; Xia, Q.; Hwang, H.M.; Ray, P.C.; Yu, H. Mechanisms of nanotoxicity: Generation of reactive oxygen species. J. Food Drug Anal. 2014, 22, 64-75. [CrossRef]

15. Auffan, M.; Rose, J.; Orsiere, T.; De Meo, M.; Thill, A.; Zeyons, O.; Proux, O.; Masion, A.; Chaurand, P.; Spalla, O.; et al. CeO2 nanoparticles induce DNA damage towards human dermal fibroblasts in vitro. Nanotoxicology 2009, 3, 161-171. [CrossRef]

16. Benameur, L.; Auffan, M.; Cassien, M.; Liu, W.; Culcasi, M.; Rahmouni, H.; Stocker, P.; Tassistro, V.; Bottero, J.Y.; Rose, J.; et al. DNA damage and oxidative stress induced by $\mathrm{CeO} 2$ nanoparticles in human dermal fibroblasts: Evidence of a clastogenic effect as a mechanism of genotoxicity. Nanotoxicology 2015, 9, 696-705. [CrossRef]

17. Chen, J.; Patil, S.; Seal, S.; McGinnis, J.F. Rare earth nanoparticles prevent retinal degeneration induced by intracellular peroxides. Nat. Nanotechnol. 2006, 1, 142-150. [CrossRef]

18. Zheng, Q.; Fang, Y.; Zeng, L.; Li, X.; Chen, H.; Song, H.; Huang, J.; Shi, S. Cytocompatible cerium oxide-mediated antioxidative stress in inhibiting ocular inflammation-associated corneal neovascularization. J. Mater. Chem. B 2019. [CrossRef]

19. Patil, S.; Reshetnikov, S.; Haldar, M.K.; Seal, S.; Mallik, S. Surface-derivatized nanoceria with human carbonic anhydrase II inhibitors and fluorophores: A potential drug delivery device. J. Phys. Chem. C 2007, 111, 8437-8442. [CrossRef]

20. Hanafy, B.I.; Cave, G.W.V.; Barnett, Y.; Pierscionek, B. Ethylene glycol coated nanoceria protects against oxidative stress in human lens epithelium. RSC Adv. 2019, 9, 16596-16605. [CrossRef]

21. Andley, U.P.; Rhim, J.S.; Chylack, L.T.; Fleming, T.P. Propagation and immortalization of human lens epithelial cells in culture. Investig. Ophthalmol. Vis. Sci. 1994, 35, 3094-3102.

22. Mittler, R. ROS Are Good. Trends Plant. Sci. 2017, 22, 11-19. [CrossRef] [PubMed]

23. Zhang, Q.; Raoof, M.; Chen, Y.; Sumi, Y.; Sursal, T.; Junger, W.; Brohi, K.; Itagaki, K.; Hauser, C.J. Circulating mitochondrial DAMPs cause inflammatory responses to injury. Nature 2010, 464, 104-107. [CrossRef] [PubMed]

24. Nasrazadani, S.; Hassani, S. Modern analytical techniques in failure analysis of aerospace, chemical, and oil and gas industries. In Handbook of Materials Failure Analysis with Case Studies from the Oil and Gas Industry; Butterworth-Heinemann: Oxford, UK, 2015; pp. 39-54.

25. Saraste, A.; Pulkki, K. Morphologic and biochemical hallmarks of apoptosis. Cardiovasc. Res. 2000, 45, 528-537. [CrossRef]

26. Lovrić, J.; Cho, S.J.; Winnik, F.M.; Maysinger, D. Unmodified cadmium telluride quantum dots induce reactive oxygen species formation leading to multiple organelle damage and cell death. Chem. Biol. 2005, 12, 1227-1234. [CrossRef] [PubMed]

27. Jana, S.K.; Banerjee, P.; Das, S.; Seal, S.; Chaudhury, K. Redox-active nanoceria depolarize mitochondrial membrane of human colon cancer cells. J. Nanoparticle Res. 2014, 16, 2441. [CrossRef]

28. Keil, V.C.; Funke, F.; Zeug, A.; Schild, D.; Müller, M. Ratiometric high-resolution imaging of JC-1 fluorescence reveals the subcellular heterogeneity of astrocytic mitochondria. Pflugers Arch. Eur. J. Physiol. 2011, 462, 693-708. [CrossRef]

29. Zamaraeva, M.V.; Sabirov, R.Z.; Maeno, E.; Ando-Akatsuka, Y.; Bessonova, S.V.; Okada, Y. Cells die with increased cytosolic ATP during apoptosis: A bioluminescence study with intracellular luciferase. Cell Death Differ. 2005, 12, 1390-1397. [CrossRef]

30. Richter, C.; Schweizer, M.; Cossarizza, A.; Franceschi, C. Control of apoptosis by the cellular ATP level. FEBS Lett. 1996, 378, 107-110. [CrossRef]

31. Kleiman, N.J.; Spector, A. DNA single strand breaks in human lens epithelial cells from patients with cataract. Curr. Eye Res. 1993, 12, 423-431. [CrossRef] 
32. Dayem, A.A.; Hossain, M.K.; Lee, S.B.; Kim, K.; Saha, S.K.; Yang, G.M.; Choi, H.Y.; Cho, S.G. The role of reactive oxygen species (ROS) in the biological activities of metallic nanoparticles. Int. J. Mol. Sci. 2017, 18, 120. [CrossRef] [PubMed]

33. Shi, Y. Caspase activation, inhibition, and reactivation: A mechanistic view. Protein Sci. 2004, 13, $1979-1987$. [CrossRef] [PubMed]

34. Pagliari, F.; Mandoli, C.; Forte, G.; Magnani, E.; Pagliari, S.; Nardone, G.; Licoccia, S.; Minieri, M.; Di Nardo, P.; Traversa, E. Cerium oxide nanoparticles protect cardiac progenitor cells from oxidative stress. ACS Nano 2012, 6, 3767-3775. [CrossRef] [PubMed]

35. Rai, Y.; Pathak, R.; Kumari, N.; Sah, D.K.; Pandey, S.; Kalra, N.; Soni, R.; Dwarakanath, B.S.; Bhatt, A.N. Mitochondrial biogenesis and metabolic hyperactivation limits the application of MTT assay in the estimation of radiation induced growth inhibition. Sci. Rep. 2018, 8, 1531. [CrossRef]

36. Kwon, H.J.; Cha, M.Y.; Kim, D.; Kim, D.K.; Soh, M.; Shin, K.; Hyeon, T.; Mook-Jung, I. Mitochondria-Targeting Ceria Nanoparticles as Antioxidants for Alzheimeŕs Disease. ACS Nano 2016, 10, 2860-2870. [CrossRef]

37. Pinna, A.; Malfatti, L.; Galleri, G.; Manetti, R.; Cossu, S.; Rocchitta, G.; Migheli, R.; Serra, P.A.; Innocenzi, P. Ceria nanoparticles for the treatment of Parkinson-like diseases induced by chronic manganese intoxication. RSC Adv. 2015, 5, 20432-20439. [CrossRef]

38. Volpe, C.M.O.; Villar-Delfino, P.H.; Dos Anjos, P.M.F.; Nogueira-Machado, J.A. Cellular death, reactive oxygen species (ROS) and diabetic complications review-Article. Cell Death Dis. 2018, 9, 119. [CrossRef]

39. Pollreisz, A.; Schmidt-Erfurth, U. Diabetic Cataract-Pathogenesis, Epidemiology and Treatment. J. Ophthalmol. 2010, 2010. [CrossRef]

40. Heckert, E.G.; Seal, S.; Self, W.T. Fenton-like reaction catalyzed by the rare earth inner transition metal cerium. Environ. Sci. Technol. 2008, 42, 5014-5019. [CrossRef]

41. Singh, S.; Kumar, A.; Karakoti, A.; Seal, S.; Self, W.T. Unveiling the mechanism of uptake and sub-cellular distribution of cerium oxide nanoparticles. Mol. Biosyst. 2010, 6, 1813-1820. [CrossRef]

42. Asati, A.; Santra, S.; Kaittanis, C.; Perez, J.M. Surface-charge-dependent cell localization and cytotoxicity of cerium oxide nanoparticles. ACS Nano 2010, 4, 5321-5331. [CrossRef] [PubMed]

43. Singh, S.; Ly, A.; Das, S.; Sakthivel, T.S.; Barkam, S.; Seal, S. Cerium oxide nanoparticles at the nano-bio interface: Size-dependent cellular uptake. Artif. Cells, Nanomed. Biotechnol. 2018, 46, S956-S963. [CrossRef] [PubMed]

44. Pierscionek, B.K.; Li, Y.; Schachar, R.A.; Chen, W. The effect of high concentration and exposure duration of nanoceria on human lens epithelial cells. Nanomed. Nanotechnol. Biol. Med. 2012, 8, 383-390. [CrossRef] [PubMed]

45. Pierscionek, B.K.; Keenan, J.; Yasseen, A.; Colhoun, L.M.; Li, Y.B.; Schachar, R.A.; Chen, W. CeO nanoparticles have no detrimental effect on eye lens proteins. Curr. Anal. Chem. 2010, 6, 172-176. [CrossRef]

46. Fröhlich, E. The role of surface charge in cellular uptake and cytotoxicity of medical nanoparticles. Int. J. Nanomedicine 2012, 7, 5577-5591. [CrossRef]

Sample Availability: Not available.

(C) 2020 by the authors. Licensee MDPI, Basel, Switzerland. This article is an open access article distributed under the terms and conditions of the Creative Commons Attribution (CC BY) license (http://creativecommons.org/licenses/by/4.0/). 